\title{
Lethal skeletal dysplasia owing to double heterozygosity for achondroplasia and spondyloepiphyseal dysplasia congenita
}

Department of

Clinical Genetics, City Hospital, Hucknall Road, Nottingham

NG5 1 PB.

I D Young

Department of Child Health, City Hospital, Nottingham.

N R Ruggins

N Rutter

\section{Department of} Radiology, City

Hospital, Nottingham. $\mathrm{J}$ M Somers

\section{Department of} Pathology, University Hospital, Nottingham. $\mathrm{J}$ M Zuccollo

Correspondence to Dr Young.

Received 7 April 1992. Accepted 27 April 1992.

\begin{abstract}
A male infant with lethal short limbed dwarfism is described. His father had spondyloepiphyseal dysplasia congenita and his mother had achondroplasia. It is believed that the infant inherited both of these disorders and that their combined effects resulted in early death owing primarily to severe pulmonary hypoplasia. ( $\mathcal{F}$ Med Genet 1992;29:831-3)
\end{abstract}

Achondroplasia and spondyloepiphyseal dysplasia congenita (SEDC) are well recognised skeletal disorders with estimated incidences of approximately 1 in $30000^{1}$ and 1 in $300000^{2}$ respectively. Both conditions usually show autosomal dominant inheritance. This paper presents the clinical and radiological features in a severely dwarfed dead neonate whose father had SEDC and mother achondroplasia.

\section{Case report}

The baby was the first child of unrelated Caucasian parents both of whom had a skeletal dysplasia. Ultrasonography at 16 weeks' gestation showed short limbs. By 32 weeks polyhydramnios was present and the chest was noted to be very small. He was delivered by elective Caesarean section at 38 weeks with a birth weight of $2810 \mathrm{~g}$ (10th centile). His condition was good at birth with Apgar scores of 7 and 9 at one and five minutes respectively.
However, by the age of 1 hour he had developed signs of respiratory distress and required ventilation from the age of 12 hours onwards.

On examination he was noted to have a large head $(\mathrm{OFC}=39 \mathrm{~cm},>97$ th centile), with a flat nasal bridge and short neck (fig 1). His chest was short and narrow with a circumference of $32 \mathrm{~cm}$ (10th centile) and his abdomen was very distended. All limbs showed marked rhizomelic shortening with short stubby fingers giving a trident shaped hand. Each hand measured $5 \mathrm{~cm}(<-2 \mathrm{SD})$ from the distal wrist crease to the tip of the middle finger which was $2 \mathrm{~cm}$ $(<-2 \mathrm{SD})$ long. There were bilateral single palmar creases. Both feet measured $6 \mathrm{~cm}$ $(<-2 \mathrm{SD})$ and showed mild talipes equinovarus. The palate was intact and the genitalia were those of a normal male.

The baby's dependence on ventilation and oxygen requirements increased culminating in death at the age of 9 days as a result of severe pulmonary hypoplasia. Permission was granted for only a limited necropsy. Rib cartilage showed normal chondrocytes separated by homogeneous matrix with normal lacunae and vascularity.

Radiographs confirmed the clinical findings of a large head and very small chest (fig 2 ). The long bones were very short with slightly widened, notched metaphyses and absent epiphyseal ossification centres at the knee, talus, and calcaneum. The ribs were short and there was generalised platyspondyly with normal
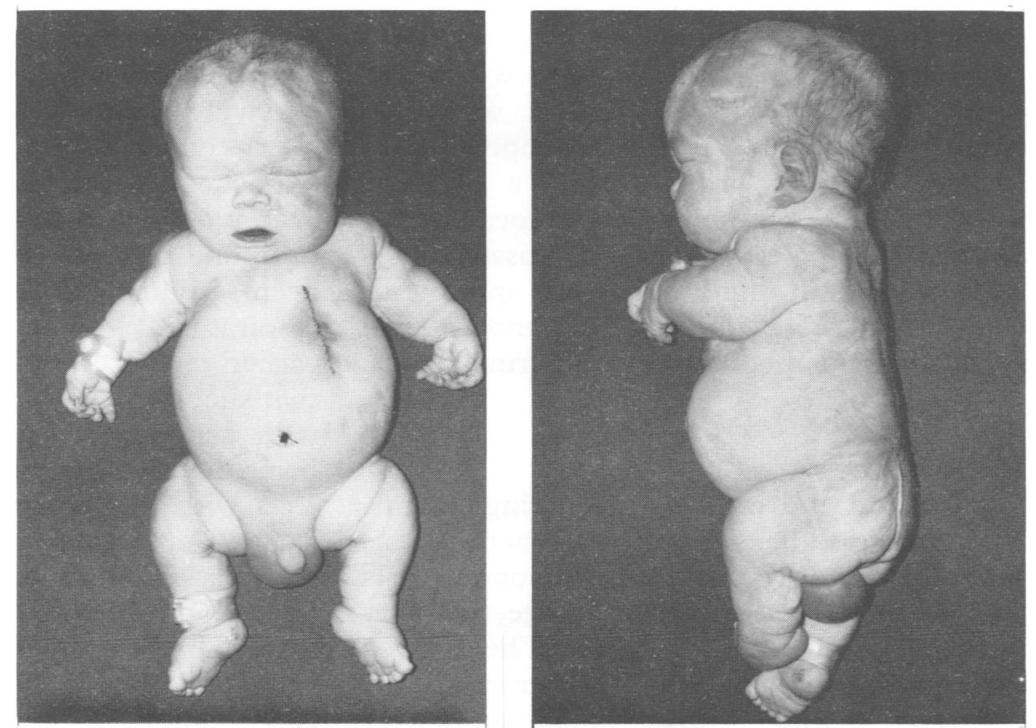

Figure 1 AP and lateral postmortem views of the baby. 


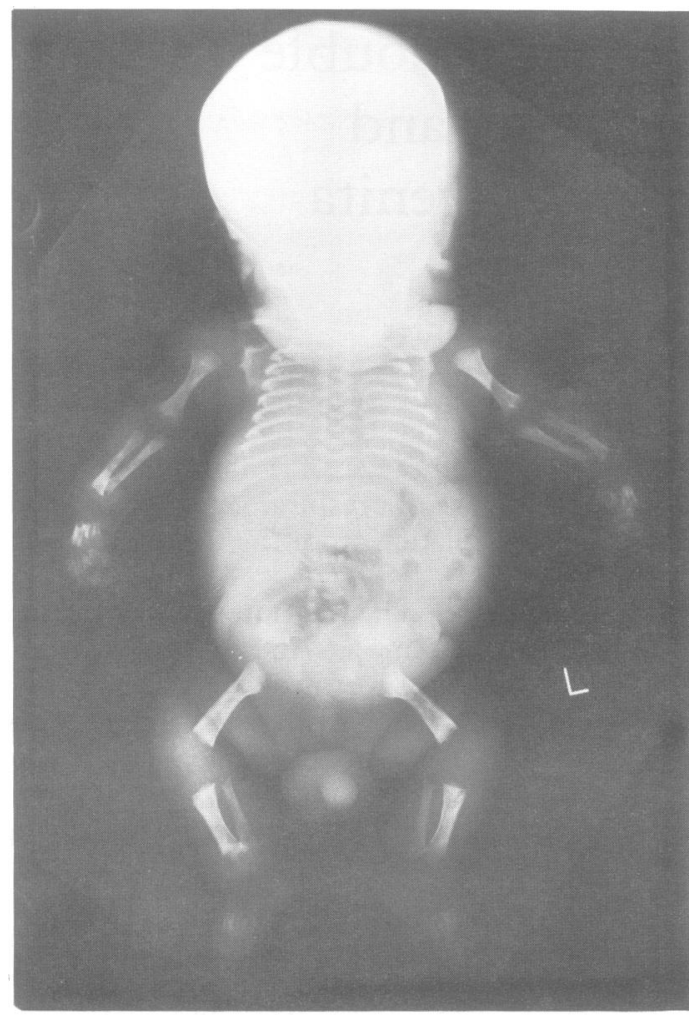

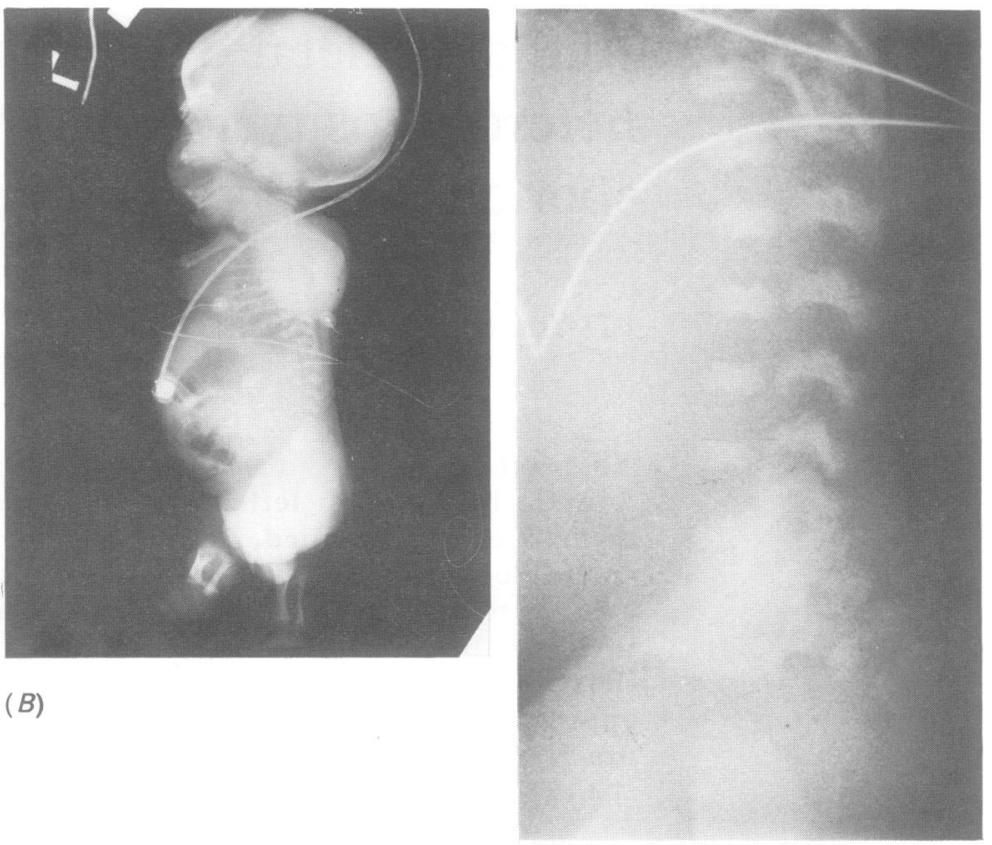

$(C)$

Figure $2 A P(A)$ and lateral $(B)$ radiographs of the baby showing marked rhizomelia with large head and small chest. The metaphyses, particularly at the knee, are notched and sloping. The iliac bones are squared with flat acetabular roofs and lateral spurs. The sacrosciatic notches are small. All of the above are features of achondroplasia. Note also the absence of ossification at the pubis, knee, and hind foot. The interpedicular distances in the lumbar spine are normal. $C 1$ and $C 2$ vertebral bodies are hypoplastic. The lateral lumbar spine (C) shows platyspondyly with a decrease in size of the vertebral bodies distally. These are all features of SEDC.

interpedicular distances in the lumbosacral vertebrae. The iliac bones were short and squat and had flat acetabular roofs. Ossification in the pubic bones was defective.

The mother of this infant had achondroplasia as did her father and sister. The father, the only child of healthy unrelated parents, was diagnosed as having SEDC at the age of $2 \frac{1}{2}$ years by Professor C O Carter. At birth he had a short trunk and limbs with bilateral talipes equinovarus. Radiographs at that time showed absence of epiphyseal ossification at the knees, calcaneum, talus, and pubic bones (fig 3). $\mathrm{He}$ had mild respiratory distress in the neonatal period and underwent repair of bilateral inguinal herniae at the age of 4 months. He enjoyed good general health and was active during childhood. By 16 years, when his height was $102 \mathrm{~cm}$, he had developed a very marked lumbar lordosis with a thoracic kyphoscoliosis. Both hips were dislocated with small dysplastic epiphyses and gross disorganisation of both joints. His facial appearance was normal with intact palate and he had relatively long upper limbs with normal hands.

\section{Discussion}

The clinical and radiological findings in this baby suggest that he inherited both of his parents' disorders. Features of achondroplasia were his large head, low nasal bridge, rhizomelia, small chest, and short hands. The notched and sloping metaphyses together with the squared iliac wings with acetabular spurs were also typical of achondroplasia. Although the interpedicular distances were normal throughout the lumbar spine, this does not exclude a diagnosis of achondroplasia at birth. The short neck and trunk were more suggestive of SEDC as was the absence of ossification at the pubis, knee, talus, and os calcis. The 'sawn off' appearance of the femoral necks was also typical of SEDC as was the generalised platyspondyly with a decrease in size of the vertebral bodies from $\mathrm{L} 1$ to $\mathrm{L} 5$.

It is generally accepted that, in contradiction to the original definition of dominance in classical genetics, most autosomal dominant disorders are very severe in the homozygous state. ${ }^{3}$ Homozygous achondroplasia usually results in early death as a consequence of respiratory insufficiency, although rare examples of survival beyond infancy have been reported. ${ }^{4}$ The combination of achondroplasia with hypochondroplasia has been described in a 14 year old girl with severe short stature and profound mental retardation which may have been secondary to several episodes of cardiorespiratory arrest and hydrocephalus. ${ }^{5}$ In an earlier report of this child it was concluded that she was likely to be a genetic compound, with achondroplasia and hypochondroplasia being allelic, since in previously reported subjects with two dominant genes there was no suggestion of an interactive effect. ${ }^{6}$ The recent observation that in at least some families hypochondroplasia cosegregates with the insulin-like growth factor 1 (IGF-1) gene on chromosome $12 \mathrm{q} 23$ should facilitate rapid confirmation or rejection of this proposed achondroplasia/hypochondroplasia allelism. ${ }^{7}$ 
(A)

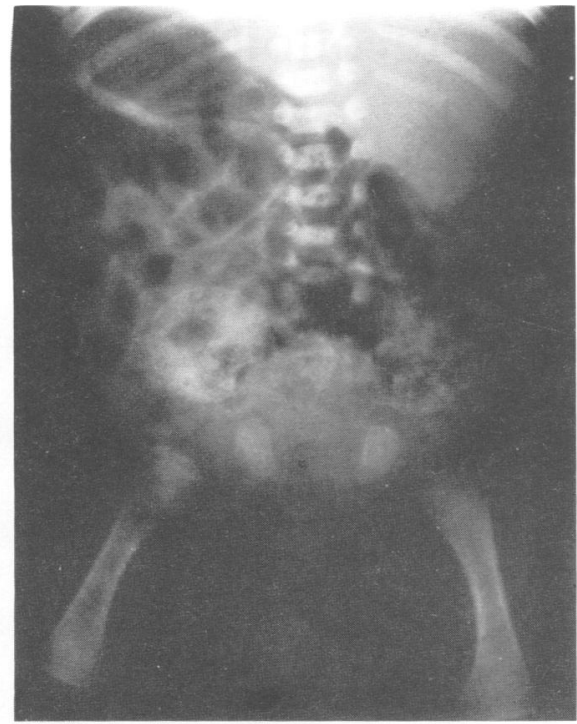

$(B)$

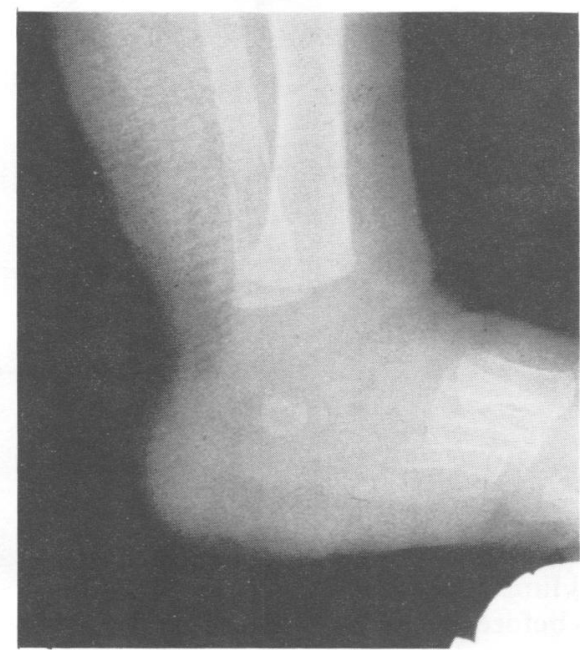

Figure 3 Radiographs of the father at birth showing typical features of SEDC. The Figure 3 Radiographs of the father at birth showing typical features of SEDC. The
$A P$ radiograph of the pelvis $(A)$ shows absence of ossification of the pubis with normal AP radiograph of the pelvis $(A)$ shows absence of ossification of the pubis with normal absent ossification of the talus $(B)$ and of the distal femoral and proximal tibial epiphyses (C). The lateral radiograph of the lumbar spine (D) illustrates the progressive decrease in size of the lumbar vertebral bodies as shown in the son.
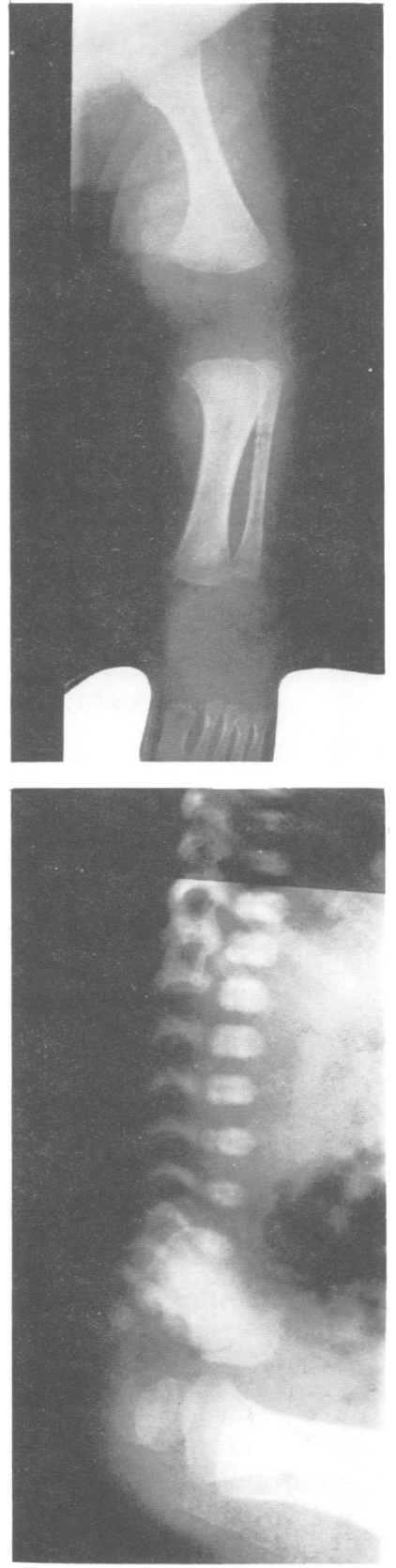

\section{(D)}

While it may emerge that achondroplasia and hypochondroplasia are indeed allelic, it is very unlikely that this applies to achondroplasia and SEDC. Accumulating evidence points towards most if not all cases of SEDC being the result of defects in type II collagen, ${ }^{8}$ the gene for which (COL2A1) maps to chromosome $12 \mathrm{q} 14.3$. This gene has been excluded as the mutant locus in achondroplasia. ${ }^{910}$ Thus it appears that it is the doubly heterozygous interaction of achondroplasia and SEDC, with the disorders acting synergistically, which is likely to have accounted for the very severe lethal skeletal abnormalities in the infant described here. This implies a recurrence risk of 1 in 4 in the event that this couple embark upon further pregnancies and suggests that two different disorders acting on the skeletal system during embryogenesis and fetal life can exert an adverse interactive effect.
1 Gardner RJM. A new estimate of the achondroplasia mutation rate. Clin Genet 1977;11:31-8.

Wynne-Davies $R$, Hall $C$. Two clinical variants of spon[Br] 1982;64:435-41.

Pauli RM. Dominance and homozygosity in man. $A m \mathcal{F}$ Med Genet 1983;16:455-8.

4 Pauli RM, Conroy MM, Langer LO, et al. Homozygous achondroplasia with survival beyond infancy. $A m \mathcal{F} M e d$ Genet 1983;16:459-73.

5 Sommer A, Young-Wee T, Frye T. Achondroplasia-hypochondroplasia complex. Am f Med Genet 1987;26:949-57.

6 McKusick VA, Kelly TE, Dorst JP. Observations suggesting allelism of the achondroplasia and hypochondroplasia genes. I Med Genet 1973;10:11-16.

7 Mullis PE, Patel MS, Brickell PM, Hindmarsh PC, Brook CGD. Growth characteristics and response to growth hormone therapy in patients with hypochondroplasia: hormone therapy in patients with hypochondroplasia: genetic linkage of the insulin-like growth factor 1 gene at
chromosome 12q23 to the disease in a subgroup of these chromosome 12q23 to the disease in a subgr

patients. Clin Endocrinol 1991;34:265-74.
8 Murray LW, Bautista J, James PL, Rimoin DL. Type II collagen defects in the chrondrodysplasias. 1. Spondylo-

9 Ogilvie D, Wordsworth P, Thompson E, Sykes B. Evidence against the structural gene encoding type II collagen (COL2A1) as the mutant locus in achondroplasia. $\mathcal{f}$ Med Genet 1986;23:19-22.

10 Francomana CA, Pyeritz RE. Achondroplasia is not caused by mutation in the gene for type II collagen. Am $\mathcal{f}$ Med Genet 1988;29:955-61. dyloepiphyseal dysplasia congenita. F Bone foint Surg epiphyseal dysplasias. Am 7 Hum Genet 1989;45:5-15. 